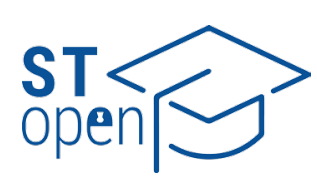

(c) 2021 The Author(s)

ST-OPEN \ 2021

\title{
Effect of poly(ethylene oxide) sample preparation on the results of thermogravimetric analysis
}

\author{
Anđela Čović, \\ Nataša Stipanelov \\ Vrandečić
}

University of Split, Faculty of Chemistry and Technology, Split, Croatia
Correspondence to:

Anđela Čović

Ruđera Boškovića 35, 21000 Split, Croatia ac6352@ktf-split.hr

\section{Cite as:}

Čović A, Stipanelov Vrandečić N. Effect of poly(ethylene oxide) sample preparation on the results of thermogravimetric analysis. ST-OPEN. 2021; 2: e2021.1806.8.
Aim: To investigate whether the sample preparation process of poly(ethylene oxide) (PEO) affects kinetic analysis of the thermal degradation process. Kinetic analysis was performed to describe the course of a chemical reaction regardless of the reaction conditions and the reaction system complexity. One differential method, the Friedman method, and one integral Kissinger-Akahira-Sunose method (KAS), were applied in this work.

Methods: The PEO sample was prepared in 4 different ways. Thermogravimetric analysis was performed to determine the thermal degradation of prepared samples. Infrared spectroscopic analysis was performed during the preparation of the PEO film obtained by casting from the solution.

Results: Dynamic thermal decomposition of PEO, regardless of the method of preparation, takes place through a single decomposition stage, which is manifested by the appearance of one peak on derivative thermogravimetric (DTG) curve. During the preparation of the PEO film, the procedure was carried out at a temperature higher than its melting temperature $\left(T_{\mathrm{m}}=65^{\circ} \mathrm{C}\right)$. After the cooling, the obtained sample didn't solidify and it had an intense odor of acetic acid, which was confirmed by infrared spectroscopic analysis. Samples III and IV were re-prepared at a temperature lower than the melting point of PEO, obtaining samples of satisfactory quality.

Conclusion: In order to prepare poly(ethylene oxide) films by solution casting technique, drying should be carried out at temperatures below the melting point of PEO. If TG analysis of pure PEO powder is compared with the results of hot pressed samples and solution cast samples, it can be concluded that the preparation of the sample doesn't affect the thermal stability of the PEO. The dependence of activation energy calculated by the differential Friedman and integral KAS method on conversion is constant for all samples in a broad conversion range, regardless of how the samples were prepared. The hot pressed samples and solution cast samples have lower activation energy than the commercial PEO powder. 


\section{Introduction}

Poly(ethylene oxide) (PEO) is a relatively cheap, conductive, water-soluble and biodegradable polymer. It shows excellent processability, mechanical properties and has a very wide application in various fields of industry. It is used as a component of packaging materials, in the textile industry and coating industry, as a solid electrolyte in batteries, as a material for thermal energy storage and in the manufacture of dosage forms with controlled release of the active substance [1-5]. During their lifetime, polymers are constantly exposed to various loads and interactions with the environment. Their gradual decomposition results in deterioration of many properties from mechanical, chemical, thermal or electrical, to changes in color and appearance [6, 7]. Thermal decomposition research is important for understanding the processing, storage and recovery of polymers, and its possible recycling. Often, the process of thermal decomposition of polymeric materials is investigated by dynamic thermogravimetric analysis. Experimental data collected by this method allow the implementation of kinetic analysis of thermally activated heterogeneous chemical reactions such as polymer degradation. The calculation of the rate and kinetic parameters of the process has a great practical significance, especially for determining the stability of materials in terms of processing and application, as well as in predicting the useful life of products. There are different methods for determining kinetic parameters, but is generally accepted today that for reliable determination of kinetic parameters, it is necessary to accurately determine the dependence of activation energy on conversion [8,9].

The aim of this work is to investigate whether the preparation of a polymer sample affects the activation energy values calculated on the basis of thermogravimetric analysis data.

\section{Kinetic analysis}

Thermal decomposition of polymers in most cases is a complex process, with series of parallel and/or sequential elementary stages, activated by the thermal energy from outside. The aim of kinetic analysis of the thermal decomposition process is to calculate the kinetic parameters of the investigated process and determine their dependence on the process variables. Experimental data required for the kinetic analysis of thermally activated heterogeneous chemical reactions are obtained using thermoanalytical methods such as thermogravimetric analysis (TG), differential scanning calorimetry (DSC) and differential thermal analysis (DTA), under isothermal and dynamic conditions [10]. Since these techniques aren't able to detect elementary reactions and their sequence, but only the total change in the observed physical properties, they don't provide any information about the mechanism of the chemical reaction. Therefore, such techniques are often used in combination with Fourier-transform infrared spectroscopy (FTIR), gas chromatography (GC) and mass spectroscopy (MS), for the analysis of gaseous reaction products, or X-ray diffraction analysis (XRD) and FTIR for analysis of solid reaction products. The kinetic analysis of the experimental data is performed by the kinetic equation for one-step reactions, which is defined as the product of two functions. One depends on the temperature and the other on the degree of conversion [8-12]: 


$$
r=\frac{\mathrm{d} \alpha}{\mathrm{d} t}=k(T) \cdot f(\alpha)
$$

where $r$ is the reaction rate $\left(\mathrm{min}^{-1}\right), k(T)$ is constant of the reaction rate $\left(\mathrm{min}^{-1}\right), f(\alpha)$ is the analytical form of the function of degree of conversion, $T$ the absolute temperature (K), $t$ is the time ( $\mathrm{min})$ and $\alpha$ is the conversion. For TG measurements, conversion is defined as the ratio of mass losses at any given time and total mass loss for a given stage of the decomposition process:

$$
\alpha=\frac{m_{0}-m}{m_{0}-m_{f}}
$$

where $m$ is mass of the sample at the time $t, m_{0}$ is the initial mass of the sample and $m_{\mathrm{f}}$ is the final mass of the sample. It is assumed that the constant of the reaction rate follows the dependence of Arrhenius equation:

$$
k(T)=A \cdot \exp \left(-\frac{E}{R T}\right)
$$

where $A$ is the pre-exponential factor $\left(\mathrm{min}^{-1}\right), E$ is the activation energy $\left(\mathrm{Jmol}^{-1}\right)$ and $R$ is the general gas constant $\left(8.3144598 \mathrm{JK}^{-1} \mathrm{~mol}^{-1}\right)$. It is necessary to emphasize that thermal degradation of polymers is a heterogeneous process in which a set of chemical reactions and physical processes proceed with an overall rate. For that reason, the experimentally determined kinetic parameters are called the apparent activation energy and apparent pre-exponential factor.

By including equation (3) in equation (1), the general kinetic equation is obtained [8-12]:

$$
\frac{\mathrm{d} \alpha}{\mathrm{d} t}=A \cdot \exp \left(-\frac{E}{R T}\right) \cdot f(\alpha)
$$

This equation describes the total process, and its application assumes that the calculated values of $E, A$ and $f(\alpha)$, i.e. the so-called "kinetic triplet" can describe the overall course of a process regardless of its complexity. Dynamic TG analysis is performed at a constant heating rate $\beta=\mathrm{d} T / \mathrm{d} t$, where the general kinetic equation (4) takes the form:

$$
\frac{\mathrm{d} \alpha}{\mathrm{d} t}=\beta \frac{\mathrm{d} \alpha}{\mathrm{d} T}=A \cdot \exp \left(-\frac{E}{R T}\right) \cdot f(\alpha)
$$

In integrated form, this equation as follows:

$$
g(\alpha)=\int_{0}^{\alpha} \frac{\mathrm{d} \alpha}{f(\alpha)}=\frac{A}{\beta} \int_{0}^{T} \exp \left(-\frac{E}{R T}\right) \mathrm{d} T
$$


Today is generally accepted that for reliable determination of kinetic parameters, it is necessary to record at least three experimental TG curves at different heating rates and to determine the dependence of activation energy value on conversion using isoconversional methods. Isoconversional methods, also called model-free methods, enable reliable calculation of activation energy without assuming a model $f(\alpha)$. The best known linear integral isoconversional methods are the Flynn-Wall-Ozawa (FWO) and modified KissingerAkahira-Sunose (KAS) method [12, 13], whilst the most known linear differential isoconversional method is that of Friedman (FR) [2, 8, 14, 15].

The Flynn-Wall-Ozawa and Kissinger-Akahira-Sunose methods are based on these equations:

$$
\begin{gathered}
\log \beta=\log \frac{A E}{R g(\alpha)}-2,315-0,4567 \cdot \frac{E}{R T} \\
\ln \frac{\beta}{T^{2}}=\ln \frac{A R}{E g(\alpha)}-\frac{E}{R T}
\end{gathered}
$$

Drawing the dependence of $\log \beta$, i.e. $\ln \left(\beta / T^{2}\right)$ versus $1 / T$ for each $\alpha=$ const. and by applying linear regression analysis, a series of isoconversional straight lines are obtained, from whose slope the activation energy for a certain conversion is determined [2, 6, 13].

Friedman method is based on equation:

$$
\ln \left[\beta \frac{d \alpha}{d T}\right]=\ln \frac{\mathrm{d} \alpha}{\mathrm{d} t}=\ln A+\ln f(\alpha)-\frac{E}{R T}
$$

Also, drawing the dependence $\ln [\beta \mathrm{d} \alpha / \mathrm{d} T]$ versus $1 / T$ for each $\alpha=$ const. and applying linear regression analysis, a series of isoconversional straight lines are obtained, from whose slope the activation energy for a certain conversion is determined [2, 8, 15]. The dependence of the activation energy on the conversion provides an insight into the complexity of thermal decomposition process of polymers. If the activation energy doesn't change with the conversion, it can be concluded that it is a simple one-step process. On the other hand, the change in activation energy is indication of the complex, multi-step mechanism of the investigated process.

\section{Materials and methods}

\section{Materials}

In this work PEO powder, molecular weight $M \mathrm{w}=300$ 000, Polyox ${ }^{\mathrm{TM}}$ WSR N750, manufactured by The Dow Chemical Company, Midland, USA, was used. Distilled water and ethanol mixtures were used as solvent. A sample of pure PEO powder was marked as Sample I. 


\section{Preparation of the sample by hot pressing}

PEO films with thickness of $0.0576 \mathrm{~mm}$ were made using a hand hydraulic press Dynisco

LME 230, manufactured by Specac. The polymer powder was pressed for 45 seconds at a pressure of $50.99 \mathrm{Nmm}^{-2}$ at temperature of $120^{\circ} \mathrm{C}$, and is marked as Sample II (Figure 1a).

\section{Preparation of the sample in the form of a film by solution casting}

An initial 4\% solution of PEO was obtained by dissolving $4 \mathrm{~g}$ of PEO in $100 \mathrm{~mL}$ of an ethanol/distilled water solvent mixture. Three solutions with different solvent ratios were prepared:

- ethanol : distilled water $=70: 30$

- ethanol : distilled water $=50: 50$

- ethanol : distilled water $=30: 70$.

The weighed powder was transferred to a volumetric flask, covered with a portion of the solvent and left overnight to allow sufficient time for the swelling process. After that, the rest of the solvent was added and the dissolution process was carried out by heating in a water bath $\left(\mathrm{T} \approx 50^{\circ} \mathrm{C}\right)$. The volumetric flasks were cooled and refilled to the mark. Content of each flask was individually transferred to a round bottom flask connected to a water cooler and heated up to $70^{\circ} \mathrm{C}$ with reflux and constant stirring for 2 hours. Obtained milky white solutions were casted into Petri dishes. Then, samples were dried at $40^{\circ} \mathrm{C}$ for 1 day, at $50^{\circ} \mathrm{C}$ for 1 day and then in a vacuum dryer at $70^{\circ} \mathrm{C}$ for 3 days. After drying at a temperature higher than the melting temperature of PEO, a wet film of milky white color and odor of acetic acid were obtained. The sample didn't solidify after cooling. Since no films of adequate quality were obtained in the previously described process, solution was prepared by dissolving $4 \mathrm{~g}$ of PEO powder in $100 \mathrm{~mL}$ of distilled water. Content of the flask was transferred to an Erlenmeyer flask with a ground stopper, sealed and heated to $70^{\circ} \mathrm{C}$ with stirring for 2 hours. Obtained milky white solution was casted into two Petri dishes. One part of the sample was dried for 1 day at $40^{\circ} \mathrm{C}, 1$ day at $50^{\circ} \mathrm{C}$ (Sample III), while the other part of the sample was additionally dried for 3 days in a vacuum dryer (Sample IV). Drying at a temperature lower than the melting temperature of PEO allowed us to obtain clear and compact films of satisfactory quality (Figure 1c).

\section{Methods}

Thermogravimetric analysis was used to determine the thermal degradation temperature of the polymer. It was performed using a Perkin-Elmer Pyris 1 TGA thermogravimetric analysis apparatus. Samples weighed approximately $10 \pm 0.5 \mathrm{mg}$. The weight loss percentage of the sample was monitored in a temperature range from $50^{\circ} \mathrm{C}$ to $550^{\circ} \mathrm{C}$, at four heating rates $\left(\beta=2.5 ; 5 ; 10\right.$ and $\left.20^{\circ} \mathrm{Cmin}^{-1}\right)$. Nitrogen gas of ultrahigh purity $\left(20 \mathrm{mLmin}^{-1}\right)$ was used as the purging gas for the furnace chamber. Infrared spectroscopic analysis was performed using a Perkin Elmer Spectrum One spectrophotometer by the Horizontal Attenuated Total Reflectance (HATR) technique on a flat crystal of zinc selenide (ZnSe, angle of incidence $45^{\circ}$ ), in the wavelength range $4000-650 \mathrm{~cm}^{-1}$. Signals were collected in 
10 scans at a spectral resolution of $4 \mathrm{~cm}^{-1}$ and rationed against a background spectrum recorded from the empty ZnSe crystal at room temperature.

\section{Results and discussion}

\section{Sample preparation and FT-IR spectroscopy}

Sample I was analyzed in pure powder form as supplied by the manufacturer. The hot pressing process yielded a clear and compact film of satisfactory quality (Figure 1a), designated as Sample II. Special attention was given to obtaining the film by casting it out of solution. After casting and drying at the temperature higher than the melting temperature of PEO, a wet film of milky white color and odor of acetic acid was obtained which, after cooling, didn't solidify and remained in the form of a viscous gel (Figure 1b). An intense odor on acetic acid led to the assumption that a chemical change of the polymer occurred during drying above the melting point.

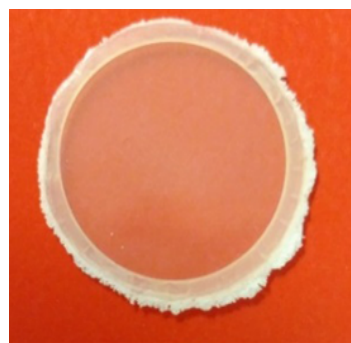

a)

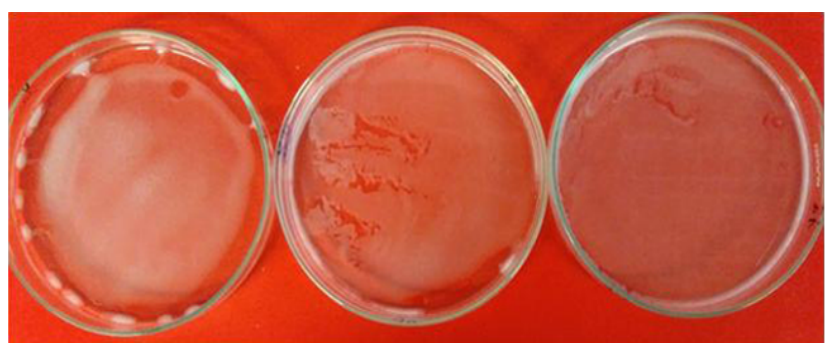

b)

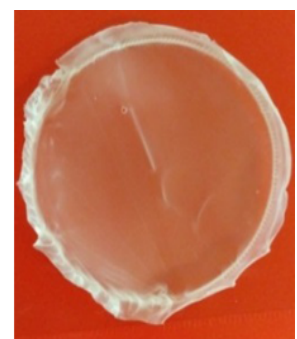

c)

Figure 1. a) Sample II hot pressed film b) Casted film dried at a temperature higher than the melting point of poly(ethylene oxide) c) Casted film dried at a temperature lower than the melting point of poly(ethylene oxide).

To confirm this assumption, FT-IR spectroscopy analysis was performed. Figure 2 shows the spectrum of Sample I and casted film dried at a temperature higher than the melting point of PEO.

\section{FTIR spectrum}

The most significant changes in the absorption band of the PEO powder sample were identified in the wavelength range $2500-3000 \mathrm{~cm}^{-1}$ and in the range $800-1500 \mathrm{~cm}^{-1}$. According to the data in the literature [16], the bands at the wave number $840 \mathrm{~cm}^{-1}$ are attributed to the oscillating vibrations of the $\mathrm{CH}_{2}$ group and the shear deformation (scissors) of the C-O-C group. Symmetrical and asymmetric oscillating vibration and tensile vibration of the $\mathrm{CH}_{2}$ group, and stretching of the C-C bond, are found at 960 and $945 \mathrm{~cm}^{-1}$. At 1145, 1093 and $1060 \mathrm{~cm}^{-1}$ is the so-called triplet, referring to the symmetrical stretching of the C-O-C group, indicating the existence of a crystalline phase of PEO. The oscillating vibration of the $\mathrm{CH}_{2}$ group at 1360 and $1341 \mathrm{~cm}^{-1}$ represents the so-called "doublet" characteristic of PEO, and the bands at 1466 and $1456 \mathrm{~cm}^{-1}$ refer to the asymmetric and symmetric shear deformation of the $\mathrm{CH}_{2}$ group. Asymmetric and symmetrical stretching of the $\mathrm{CH}_{2}$ group at $2881 \mathrm{~cm}^{-1}$ is represented by a pronounced band. On the FT-IR spectrum of the sample dried above 
the melting point (Figure 2), smaller shifts of the characteristic peaks in relation to the spectrum of pure PEO powder are observed. In addition, a wide elongation band of the hydroxyl $\mathrm{OH}$ group at a wavelength of $3446 \mathrm{~cm}^{-1}$, a $\mathrm{CH}$ bond in the $\mathrm{CH}_{3}$ group at $2874 \mathrm{~cm}^{-1}$ and a $\mathrm{C}=\mathrm{O}$ elongation at $1720 \mathrm{~cm}^{-1}$ are clearly visible, confirming the suspicion that a chemical change occurred in the sample or acetic acid was formed. Acetic acid could be formed by the ethanol oxidation of residual from the solvent, and also from ethanol formed as a product of the thermal decomposition of PEO. Since the polymer film couldn't be obtained in this way, the procedure was repeated with $4 \%$ concentrated solutions of PEO in water. Film samples were obtained by casting from the solution whereby Sample III was dried without application of vacuum at a temperature below the melting point of PEO. Sample IV was also dried at the same temperature but additionally under vacuum. The films prepared in this way were of satisfactory quality.

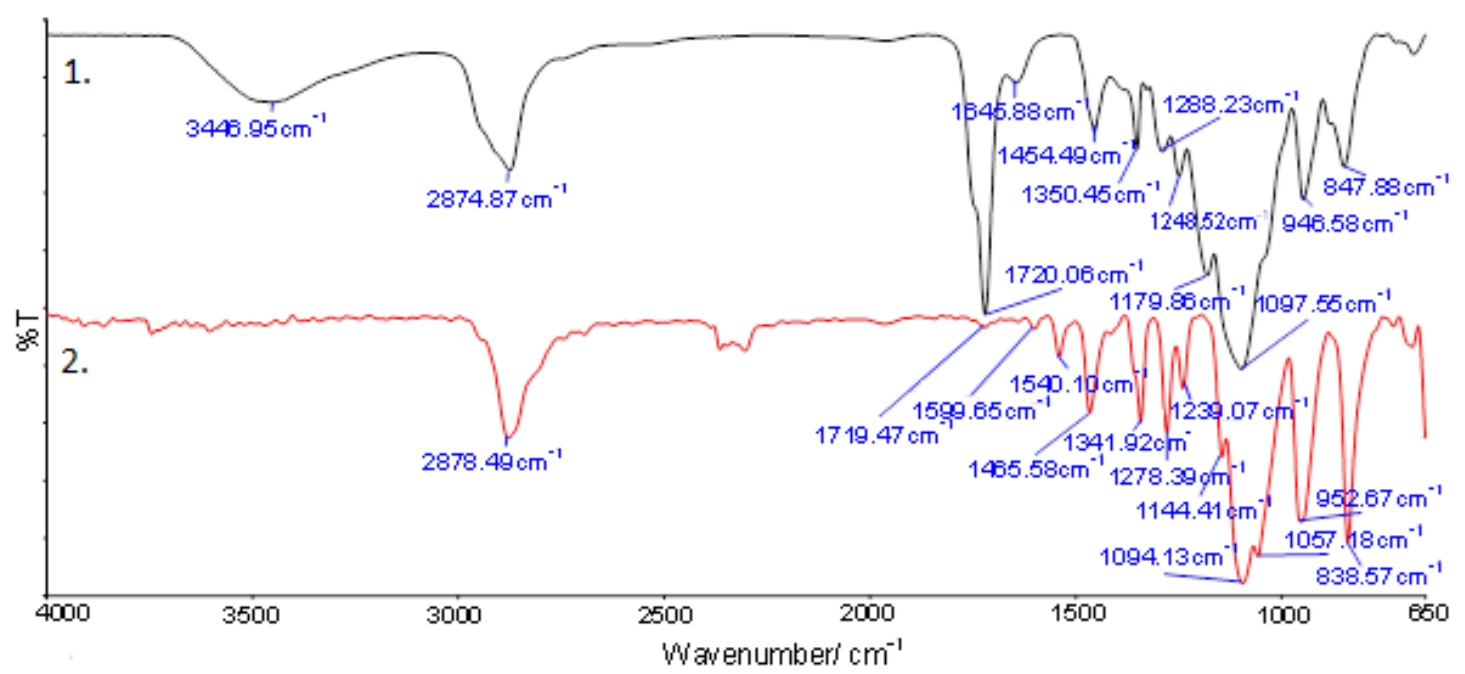

Figure 2. Comparison of FT-IR spectrum of casted film sample dried at a temperature higher than the melting point of poly(ethylene oxide) (1.) and spectrum of pure powder of poly(ethylene oxide)(2.).

\section{Thermogravimetric analysis}

The thermal decomposition of the prepared PEO samples was investigated by dynamic thermogravimetry. The result of this analysis are TG and DTG curves of dynamic thermal decomposition of PEO samples, which represent the mass loss, i.e. the rate of mass loss as a function of temperature. Obtained results are shown in Figure 3a-d.

From the shape of the TG and DTG curves, it is obvious that the thermal decomposition of all four PEO samples took place through one stage at all heating rates in the temperature range $330-450^{\circ} \mathrm{C}$. Products of thermal decomposition of PEO are low molecular weight compounds: ethanol, methanol, alkenes, non-cyclic ethers (ethoxy methane, ethoxy ethane, methoxy methane), formaldehyde, ethylene oxide, water, $\mathrm{CO}$ and $\mathrm{CO}_{2}$ [16]. When increasing the heating rate, TG and DTG curves shift to higher temperatures and the decomposition rate also increases. Characteristics of the TG and DTG curves are shown in Table 1.

It is common for the thermal stability of polymers to be estimated from the characteristics of TG curves recorded at the lowest heating rate. Decomposition of PEO powder begins at 


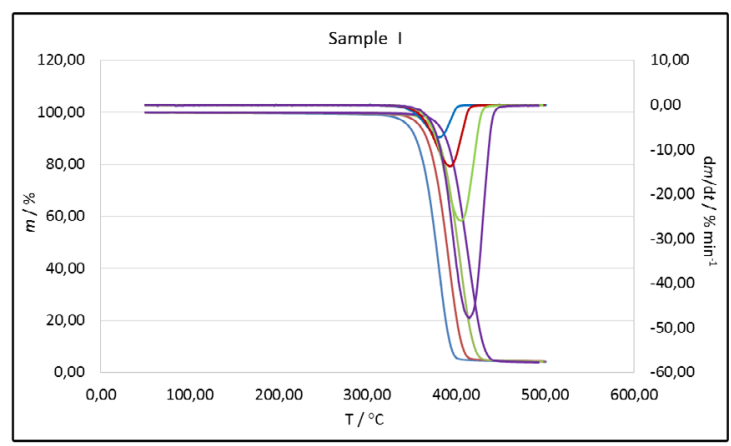

a)

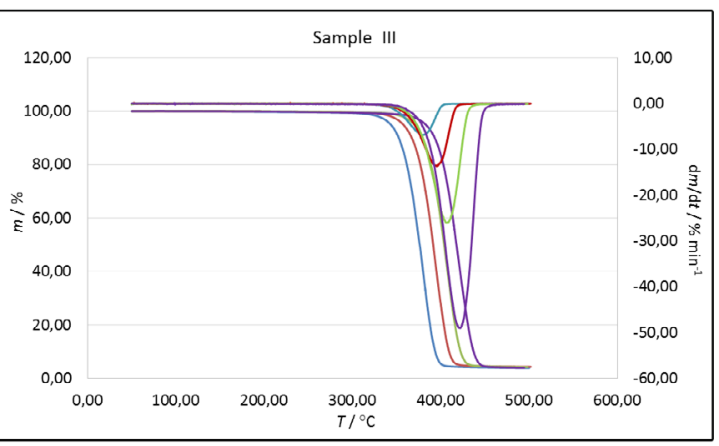

c)

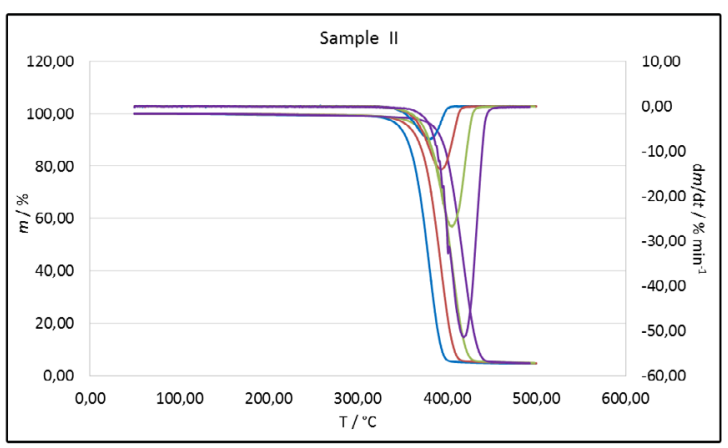

b)

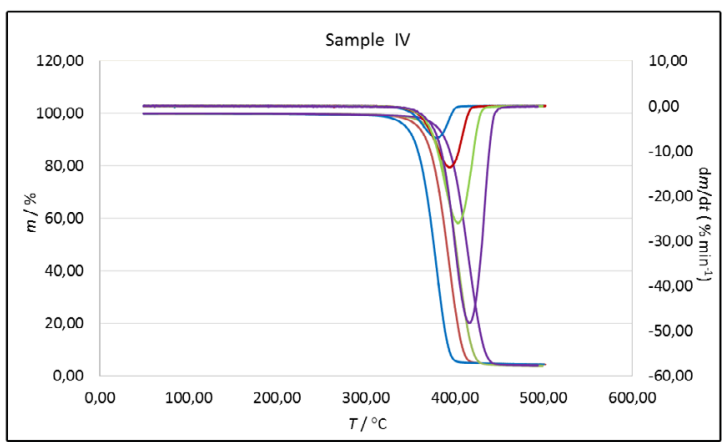

d)

$$
-2.5^{\circ} \mathrm{C} / \mathrm{min}-5^{\circ} \mathrm{C} / \mathrm{min}-10^{\circ} \mathrm{C} / \mathrm{min}-20^{\circ} \mathrm{C} / \mathrm{min}
$$

Figure 3. TG and DTG curves of dynamic decomposition at different heating rates for Sample I (a), Sample II (b), Sample III (c), and Sample IV (d).

Table 1. Characteristic of the thermal decomposition process

\begin{tabular}{|c|c|c|c|c|c|c|c|}
\hline${ }^{*} \beta /{ }^{\circ} \mathrm{C} \min ^{-1}$ & Sample & ${ }^{\dagger} T^{0} /{ }^{\circ} \mathrm{C}$ & ${ }^{\ddagger} T_{5 \%} /{ }^{\circ} \mathrm{C}$ & ${ }^{\S} T_{\max } /{ }^{\circ} \mathrm{C}$ & ${ }^{\top} R_{\max } / \% \min ^{-1}$ & $\|_{\Delta m}$ & ${ }^{* *} m_{\mathrm{f}} / \%$ \\
\hline \multirow{4}{*}{2.5} & 1 & 357 & 346 & 380 & 7.25 & 95.8 & 4.2 \\
\hline & II & 358 & 347 & 380 & 7.26 & 95.4 & 4.6 \\
\hline & III & 356 & 343 & 380 & 6.85 & 96.1 & 3.9 \\
\hline & IV & 358 & 345 & 380 & 7.13 & 95.7 & 4.3 \\
\hline \multirow{4}{*}{5} & 1 & 371 & 359 & 393 & 13.75 & 95.7 & 4.3 \\
\hline & II & 372 & 357 & 394 & 14.11 & 95.2 & 4.8 \\
\hline & III & 373 & 357 & 395 & 13.62 & 95.7 & 4.3 \\
\hline & IV & 372 & 359 & 394 & 13.61 & 95.7 & 4.3 \\
\hline \multirow{4}{*}{10} & I & 383 & 371 & 405 & 25.92 & 95.8 & 4.2 \\
\hline & II & 385 & 368 & 405 & 26.69 & 95.1 & 4.9 \\
\hline & III & 383 & 370 & 407 & 25.99 & 95.8 & 4.2 \\
\hline & IV & 382 & 369 & 404 & 26.17 & 96.3 & 3.7 \\
\hline \multirow{4}{*}{20} & I & 390 & 380 & 415 & 47.66 & 96.0 & 3.9 \\
\hline & II & 397 & 385 & 419 & 51.38 & 95.2 & 4.8 \\
\hline & III & 398 & 383 & 422 & 49.01 & 96.1 & 3.9 \\
\hline & IV & 393 & 380 & 417 & 48.30 & 96.2 & 3.8 \\
\hline
\end{tabular}

${ }^{*} B=$ heating rate, ${ }^{\circ} \mathrm{C}$ min $^{-1}$.

${ }^{\mathrm{H}} \mathrm{T}^{0}=$ initial decomposition temperature, ${ }^{\circ} \mathrm{C}$.

${ }^{\ddagger} \mathrm{T}_{5 \%}=$ temperature at weight loss of $5 \%,{ }^{\circ} \mathrm{C}$.

$\mathrm{ST}^{5 \%}=$ maximum decomposition temperature, ${ }^{\circ} \mathrm{C}$.

$R_{\text {max }}^{\max }=$ maximum decomposition rate, $\% \min ^{-1}$.

$\| \Delta m=$ sample mass change.

${ }^{* *} m_{\mathrm{f}}=$ residual mass of the sample, $\%$. 
a temperature of $357^{\circ} \mathrm{C}$, and $5 \%$ of the total mass is lost at $346^{\circ} \mathrm{C}$. The highest degradation rate of $7.25 \% \mathrm{~min}^{-1}$ is achieved at $380^{\circ} \mathrm{C}$. At temperatures above $450^{\circ} \mathrm{C}$, only $4.2 \%$ of the initial mass sample remains. Comparing these values with the values for samples II-IV, it can be concluded that the sample preparation doesn't affect the results of thermogravimetric analysis, i.e. the thermal stability of PEO.

\section{Kinetic analysis}

The kinetic analysis of degradation process is based on experimental TG curves (Figure 3a-d), from which the temperatures needed to reach each degree of conversion were read off. The analysis begins by determining the activation energy using isoconversional kinetic analysis methods that don't require the assumption of function of degree of conversion $f(\alpha)$, but require recording TG curves at different heating rates and allow the determination of the functional dependence $E$ of $\alpha$. One differential method, the Friedman method, and one integral Kissinger-Akahira-Sunose method, were applied in this work. Friedman's method is based on equation (9) which is linearized in the coordinate system of the dependence $\ln \mathrm{d} \alpha / \mathrm{d} t$ versus $1 / T$ for each $\alpha=$ const. By applying linear regression analysis, a series of isoconversional lines were obtained from whose slope $(E / R)$ the activation energy for a given conversion was calculated. An example of the data display is showed on Figure 4 for Sample I.

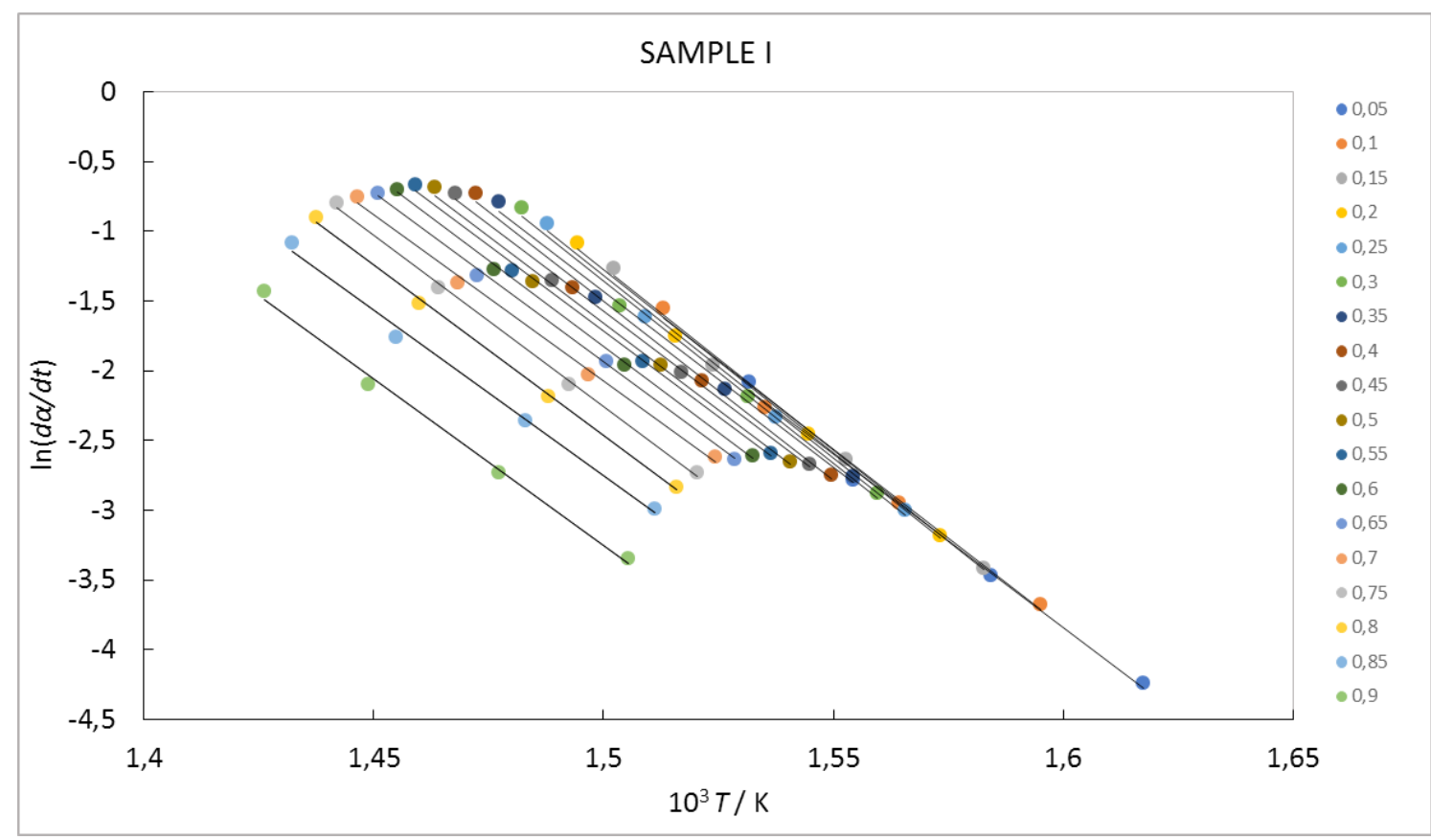

Figure 4. Isoconversional lines series obtained of by Friedman method in representation dependence of ln $\mathrm{d} \alpha / \mathrm{d} t$ versus $1 / T$ for each $\alpha=$ const.

Activation energy values at given conversions of the thermal decomposition process for all four tested samples calculated by the Friedman method are shown in Figure 5.

The average values of activation energy and standard deviation, as well as the difference between the maximum $\left(E_{\max }\right)$ and minimum $\left(E_{\min }\right)$ values of activation energy in the conversion range 0.05-0.95, are listed in Table 2. According to the recommendations for per- 


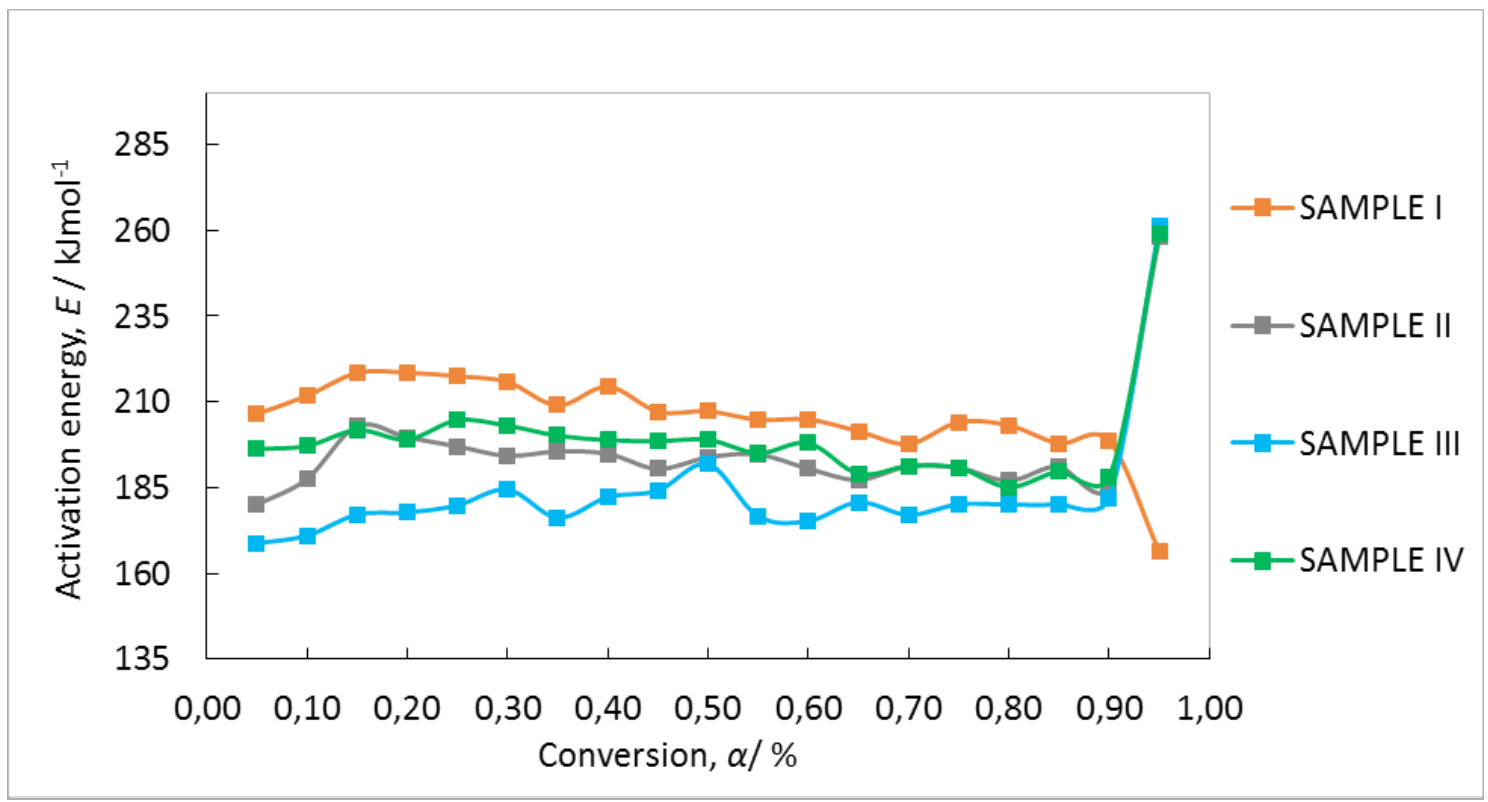

Figure 5. Activation energy values at given conversions of the thermal decomposition process for all four tested samples calculated by the Friedman method.

forming kinetic analysis [8], the dependence of activation energy on conversion can be considered constant if the difference between the maximum and minimum value of $E$ is less than $20 \%$ of the mean value of activation energy in the selected conversion area.

Table 2. Average values of activation energy and standard deviation, and the difference between the highest and lowest values of $E$ calculated by the Friedman method for all four samples

\begin{tabular}{cccc} 
Sample & $E_{\operatorname{mean}}(\alpha=0.05-0.95) / \mathrm{kJ} \mathrm{mol}^{-1}$ & $E_{\max }-E_{\min }$ & $0.2 \cdot E_{\operatorname{mean}}-\left(E_{\max }-E_{\min }\right)$ \\
I & $206 \pm 12$ & 21 & 20 \\
II & $195 \pm 16$ & 23 & 16 \\
III & $184 \pm 19$ & 23 & 14 \\
IV & $199 \pm 15$ & 74 & -34 \\
\hline
\end{tabular}

This condition is met by samples I-III for the conversion range 0.05-0.95; while sample IV satisfies in the conversion range 0.05-0.90. If $E$ changes significantly with $\alpha$, the process is characterized as kinetically complex, and the form of the dependence $E$ on $\alpha$ helps to determine the kinetic scheme of the examined process.

The Kissinger-Akahira-Sunose (KAS) method is based on equation (8) which is linearized in the coordinate system of the dependence $\ln \left(\beta / T^{2}\right)$ versus $1 / T$ for each $\alpha=$ const. By applying linear regression analysis, a series of isoconversional straight lines were obtained, from which the slope $(E / R)$ of the activation energy for a certain conversion was calculated (Figure 6).

The values of activation energy at the given conversions of the thermal decomposition process for all four tested samples calculated by the KAS method are shown in Figure 7.

The average values of activation energy and standard deviation, as well as the difference between the highest $\left(\mathrm{E}_{\max }\right)$ and minimum $\left(\mathrm{E}_{\min }\right)$ values of activation energy in the conver- 


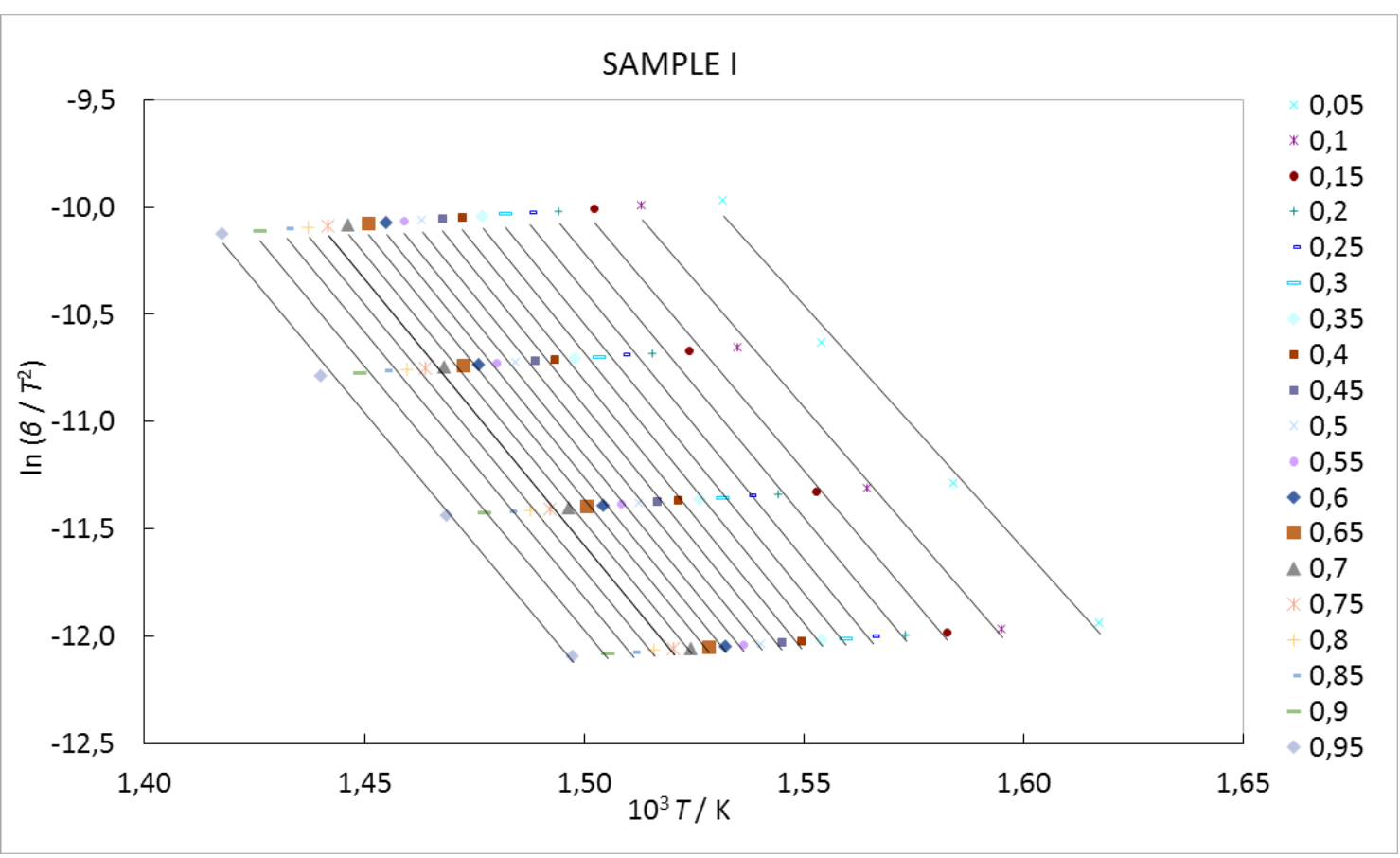

Figure 6. Isoconversional lines series obtained by KAS method in representation dependence of $\ln \left(\beta / T^{2}\right)$ versus $1 / T$ for each $\alpha=$ const.

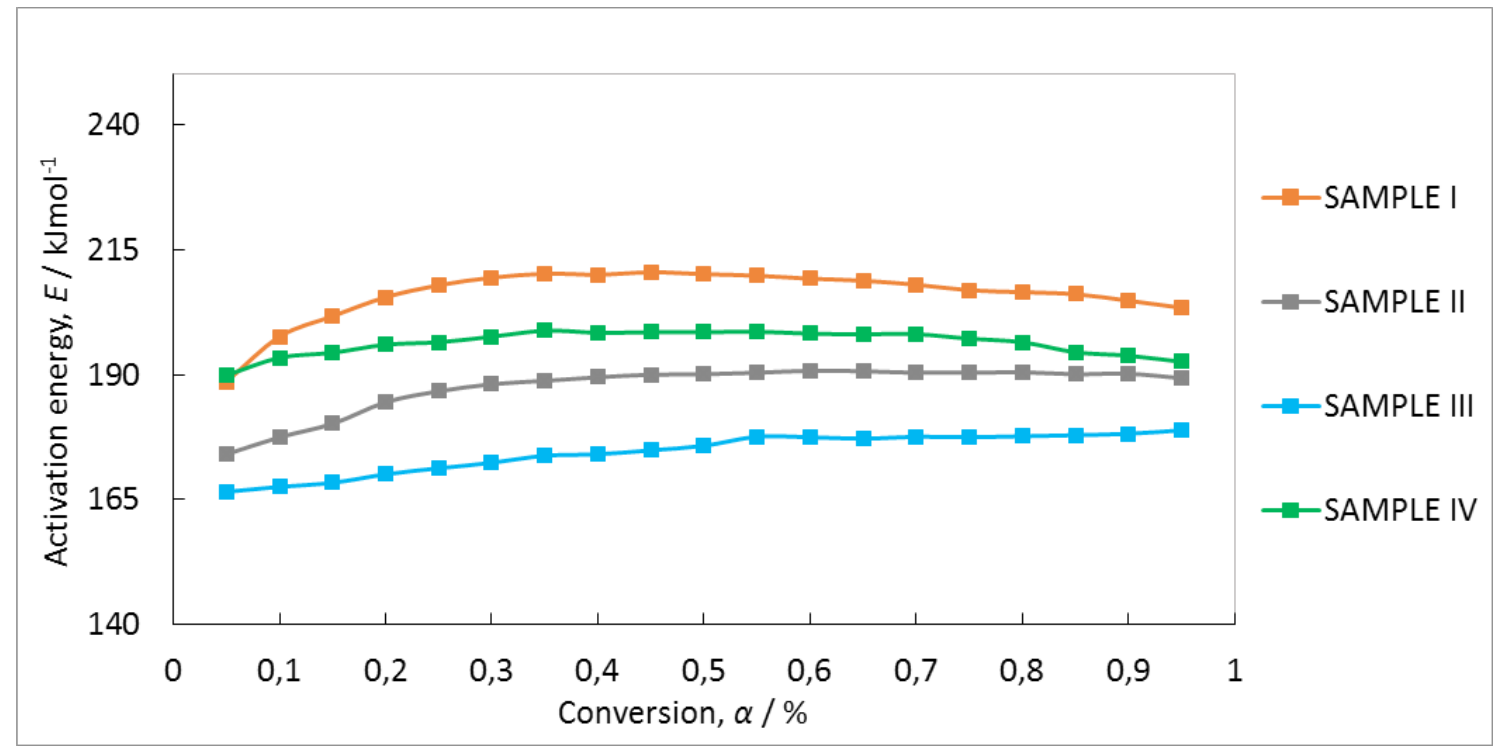

Figure 7. Activation energy at the given conversions of the thermal decomposition process for all four tested samples calculated by the KAS method.

sion range 0.05-0.95 are listed in Table 3. Activation energy values calculated by the KAS method can be considered constant in the conversion range $0.05-0.95$ for all samples, since

Table 3. Average values of activation energy and standard deviation, and the difference between the maximum and minimum values of $E$ calculated by the KAS method for all four samples

\begin{tabular}{cccc} 
Sample & $E_{\text {mean }}(\alpha=0.05-0.95) / \mathrm{kJ} \mathrm{mol}^{-1}$ & $E_{\max }-E_{\min }$ & $0.2 \cdot E_{\text {mean }}-\left(E_{\max }-E_{\min }\right)$ \\
I & $206 \pm 5$ & 22 & 19 \\
II & $187 \pm 5$ & 17 & 21 \\
III & $174 \pm 4$ & 12 & 23 \\
IV & $196 \pm 3$ & 9 & 31 \\
\hline
\end{tabular}


the difference between the maximum and minimum value of $E$ is less than $20 \%$ of the main value of activation energy in the selected conversion range.

By comparing the values of activation energy of thermal decomposition $(E)$ calculated by the differential Friedman method and the integral KAS method, it can be seen that the integral method gives slightly lower values of the activation energy of the samples obtained by hot pressing and casting out of solution. Also, the $E$ calculated by this method has a smaller deviation from the mean values. The $E$ values of pure PEO powder are higher than the activation energy values of PEO films prepared by hot pressing or casting out of solution.

Provenance: Submitted. This manuscript is based on the master's thesis by Anđela Čović, deposited in the Dabar repository (https://urn.nsk.hr/urn:nbn:hr:167:036445).

Peer review: Externally peer reviewed.

Received: 15 April 2021 / Accepted: 14 July 2021 / Published online: 19 July 2021.

Funding: This research received no specific grant from any funding agency in public, commercial or not-for-profit sectors.

Authorship declaration: NSV devised a work topic that contributed to the design, research concept, data collection, analysis and interpretation, conducted a critical audit and ongoing oversight of the work to provide final approval for the version to be published. AČ conducted the experimental part of the work and thus contributed to the collection, analysis, implementation of the estimate and the interpretation of the data. She wrote the first version of the article.

Competing interests: The authors completed the ICMJE Unified Competing Interest form (available upon request from the corresponding author), and declare no conflicts of interest.

\section{ORCID}

Nataša Stipanelov Vrandečić 이 https://orcid.org/0000-0003-0464-9133

\section{References}

1. Herman FM, Norman GG, Norbert MB. 1, 2-Epoxide Polymers: Ethylene oxide polymers. In: Encyclopedia of Polymer Science and Technology: Plastics, resins, rubbers, fibers. Volume 6. New York, London, Sydney: Interscience Publishers a division of John Wiley \& Sons, Inc.; 1997. p. 108-110.

2. Jakić M, Stipanelov Vrandečić N, Ocelić Bulatović V, Govorčin Bajsić E. Miscibility of Poly(Vinyl Chloride) with Poly(Ethylene Oxide) of Different Molecular Weights. Chemical and Biochemical Engineering Quarterly. 2016;30(1):61-71.

3. Bailey Jr. FE, Koleske JV. Chapter 4. Solution properties of poly(ethylene oxide). In: Poly(ethylene oxide). New York, San Francisco, London: Academic press; 1976. p. 29.

4. Crowley MM, Zhang F, Koleng JJ, McGinity JW. Stability of polyethylene oxide in matrix tablets prepared by hot-melt extrusion. Biomaterials. 2002;23(21):4241-4248.

5. Vrandečić NS, Erceg M, Jakić M, Klarić I. Kinetic analysis of thermal degradation of poly(ethylene glycol) and poly(ethylene oxide) of different molecular weight. Thermochim. Acta. 2010;498:7180 .

6. Blanco I. Lifetime Prediction of Polymers: To Bet, or Not to Bet-Is This the Question? Materials (Basel). 2018;11(8):1383. 
7. Abate L, Antonelli ML, Bottino FA. The regression of isothermal thermogravimetric data to evaluate degradation Ea values of polymers: A comparison with literature methods and an evaluation of lifetime predictions reliability. Part II. Polym. Degrad. Stabil. 2013;98:2291-2296.

8. Vyazovkin S, Burnham AK, Criado JM, Perez-Maqueda LA, Popescu C, Sbirrazzuoli N. ICTAC Kinetics Committee recommendations for performing kinetic computations on thermal analysis dana. Thermochim. Acta. 2011;520:1-19.

9. Pielichowski K, Njuguna J. Thermal Degradation of Polymeric Materials. Shawbury: Rapra Technology Limited; 2005. p. 40.

10. Budrugeac P. Some methodological problems concerning the kinetic analysis of non-isothermal data for thermal and thermos oxidative degradation of polymers and polymeric materials. Polym. Degrad. Stab. 2005;89:265-273.

11. Vyazovkin S. I. J. Chem. Kin. A unified approach to kinetic processing of nonisothermal data. Int. J. of Chem. Kinet. 1996;28(2):95-101.

12. Kissinger HE. Reaction Kinetics in Differential Thermal Analysis. Analytical Chemistry. 1957;29(11):1702-1706.

13. Akahira T, Sunuse TT. Joint Convention of Four Electrical Institutes. Research Report. Chiba Institute of Technology. 1971;16:22-31.

14. Friedman HL. Kinetic of thermal degradation of char-forming plastics from thermogravimetry; Application to a phenolic resin. J. Polym. Sci. 1963;6(1):183-195.

15. Jakić M, Vrandečić NS, Erceg M. The influence of poly(ethylene glycol) on thermal properties of poly(vinyl chloride)/poly(ethylene oxide) blends. J. Therm. Anal. Calorim. 2017;127:663-674.

16. Pielichowski K, Fleytuch K. Non-oxidative thermal degradation of polyethylene oxide: kinetic and thermoanalytical study. J. Anal. Appl. Pyrolysis. 2005;73:131-138. 